\title{
Suppressor of Cytokine Signaling 1 Expression Protects Oligodendrocytes from the Deleterious Effects of Interferon- $\gamma$
}

\author{
Roumen Balabanov, ${ }^{1,2}$ Krystal Strand, ${ }^{3,4}$ April Kemper, ${ }^{5}$ Ji Yeon Lee, ${ }^{1,2}$ and Brian Popko ${ }^{1,2}$ \\ ${ }^{1}$ Jack Miller Center for Peripheral Neuropathy and ${ }^{2}$ Department of Neurology, The University of Chicago, Chicago, Illinois 60637, ${ }^{3}$ Neuroscience Center and \\ ${ }^{4}$ Curriculum for Neurobiology, University of North Carolina, Chapel Hill, North Carolina 27514, and ${ }^{5}$ Department of Pathology, Wake Forest University \\ Baptist Medical Center, Winston Salem, North Carolina 27157
}

Interferon- $\gamma($ IFN- $\gamma)$ is a pleiotropic cytokine produced by T cells and natural killer cells that has been implicated as a deleterious factor in the immune-mediated demyelinating disorder multiple sclerosis. In vitro, purified developing and mature oligodendrocytes have been shown to die in the presence of IFN- $\gamma$ by apoptosis and necrosis, respectively. Moreover, transgenic expression of IFN- $\gamma$ in the CNS of mice during development results in tremor, hypomyelination, and oligodendrocyte cell loss, and IFN- $\gamma$ expression in adult animals after demyelinating insults inhibits remyelination. To examine the molecular mechanisms of IFN- $\gamma$-induced oligodendrocyte injury, we generated a transgenic mouse line [PLP/SOCS1 (proteolipid protein/suppressor of cytokine signaling 1)] that exhibits diminished oligodendrocyte responsiveness to IFN- $\gamma$ attributable to the targeted expression of SOCS1 in these cells. We demonstrate that oligodendrocytes in the PLP/SOCS1 transgenic mice are protected against the injurious effect of IFN- $\gamma$. Our data indicate that IFN- $\gamma$ exerts a direct deleterious effect on developing oligodendrocytes. The capacity of SOCS1 to inhibit the effects of IFN- $\gamma$ suggests a therapeutic approach toward protection of myelinating oligodendrocytes against the harmful effects of inflammation.

Key words: transgenic mice; SOCS1; interferon- $\gamma$; myelin; oligodendrocytes; Stat1

\section{Introduction}

Interferon- $\gamma($ IFN- $\gamma)$ is a pleiotropic cytokine produced by $\mathrm{T}$ cells and natural killer cells that is involved in a number of immune processes (Billiau, 1996). IFN- $\gamma$ is critical to the immunoregulation of autoimmune demyelinating disorders of the CNS (Panitch et al., 1987; Glabinski et al., 1999; Tran et al., 2000; Skurkovich et al., 2001; Steinman, 2001). In addition, IFN- $\gamma$ provides an intricate link between inflammation and oligodendrocyte injury. During stimulation with IFN- $\gamma$, oligodendrocytes upregulate the expression of major histocompatibility (MHC) class I molecules, as well as other surface ligands and receptors (e.g., Fas, heat shock protein-70, and tumor necrosis factor- $\alpha$ receptor) that are believed to facilitate cell-mediated cytotoxicity (Agresti et al., 1998; Pouly et al., 2000; Traugott, 2001).

IFN- $\gamma$ has the capacity to adversely affect oligodendrocytes and the process of myelination. In vitro, developing oligodendrocytes die by apoptosis, and mature oligodendrocytes succumb to necrosis in the presence of IFN- $\gamma$ (Agresti et al., 1996; Andrews et al., 1998; Baerwald and Popko, 1998; Lin et al., 2005). Transgenic expression of IFN- $\gamma$ in the CNS of mice during the first few weeks

Received Feb. 18, 2006; revised April 3, 2006; accepted April 6, 2006.

This work was supported by National Institutes of Health Grants NIH K08 NS5040901 (R.B.) and R01 NS34939 (B.P.) and the Myelin Repair Foundation (B.P.). We are appreciative of Dr. Wendy Macklin and Dr. Douglas Hilton for their kind gifts of DNA plasmids. We also acknowledge the helpful contribution of discussions with colleagues at the Myelin Repair Foundation.

Correspondence should be addressed to Brian Popko, Jack Miller Center for Peripheral Neuropathy, The University of Chicago, Department of Neurology, 5841 South Maryland Avenue, MC2030, Chicago, IL 60637. E-mail: bpopko@uchicago.edu.

DOI:10.1523/JNEUROSCI.0737-06.2006

Copyright $\odot 2006$ Society for Neuroscience $\quad$ 0270-6474/06/265143-10\$15.00/0 of postnatal development results in hypomyelination and oligodendrocyte cell loss (Corbin et al., 1996; LaFerla et al., 2000; Lin et al., 2005). Moreover, the induction of IFN- $\gamma$ expression after demyelinating insults significantly inhibits the remyelination process (Lin et al., 2006). Oligodendrocyte injury in these models has been related to dysregulation of protein synthesis and trafficking, accumulation of unfolded proteins in the endoplasmic reticulum (ER), and triggering of a proapoptotic stress response (i.e., ER stress response) (Baerwald et al., 2000; Lin et al., 2005).

The molecular mechanism of IFN- $\gamma$-mediated injury to developing oligodendrocytes, however, remains unclear. Because of the global effects of IFN- $\gamma$ on the CNS, either direct or indirect (via microglia) modes of oligodendrocyte injury are possible. Therefore, differentiating between oligodendrocyte-specific and multicellular effects would allow for a better understanding of the molecular mechanisms involved in IFN- $\gamma$-mediated oligodendrocyte injury.

Suppressors of cytokine signaling (SOCS) are a family of proteins that inhibit intracellular Janus kinase (Jak)/signal transducer and activator of transcription (Stat) signaling and effectively "switch off" the signal transduction pathway (Starr et al., 1997; Song and Shuai 1998; Stark et al., 1998; Sakamoto et al., 2000; Levy and Darnell, 2002). SOCS proteins are key intracellular regulators of cytokine-mediated homeostasis, ensuring a controlled cellular response (Yasukawa et al., 2000; Kubo et al., 2003). SOCS1 is of particular interest because of its function as a regulator of cellular responsiveness to IFN- $\gamma$ (Starr et al., 1998; Alexander et al., 1999; Bullen et al., 2001; Chong et al., 2001; Tunley et al., 2001, 2002; Federici et al., 2002). Interestingly, the levels of SOCS1 expression in the CNS under both normal and 
inflammatory conditions are very low and virtually undetectable in oligodendrocytes (Polizzotto et al., 2000; Maier et al., 2002; Wang and Campbell, 2002).

In this report, we describe a transgenic line of mice that ectopically expresses SOCS1 in oligodendrocytes under the transcriptional control of the gene encoding the myelin protein proteolipid protein (PLP). PLP/SOCS1 mice exhibit a normal phenotype with diminished oligodendrocyte responsiveness to IFN- $\gamma$. Moreover, we demonstrate that enforced expression of SOCS1 protects oligodendrocytes against the injurious effects of IFN- $\gamma$ during development.

\section{Materials and Methods}

PLP/SOCS1 mouse line. The transgenic mouse line PLP/SOCS1 was generated using a construct containing a PLP expression cassette and SOCS1 cDNA (see Fig. 1A). The PLP expression cassette (a kind gift from Dr. Wendy Macklin, Cleveland Clinic, Cleveland, $\mathrm{OH}$ ) has been described previously and has been used for oligodendrocyte-specific expression of a number of transgenes (Wight et al., 1993; Fuss et al., 2000; Doerflinger et al., 2003; Gonzales et al., 2005). We used an SOCS1 cDNA clone (kindly provided by Douglas Hilton, Walter and Eliza Hall Institute, Melbourne, Victoria, Australia) (Starr et al., 1998) that contained a Flagepitope sequence that served as a marker for SOCS1 expression in PCRbased or anti-Flag antibody-based detection methods (Einhauer and Jungbauer, 2001). Briefly, the Flag-SOCS1 cDNA was excised from the original expression vector $\mathrm{pEF}-\mathrm{FLAG}-\mathrm{I} / \mathrm{m} 4 \mathrm{~A} 2$ with $\mathrm{XbaI}$. The fragment was Klenow filled and subcloned into an intermediate vector (modified pNEB/193 vector) at the SmaI restriction site. The resulting pNEB193/ SOCS1 vector was further digested with AscI (partial digestion) and PacI to release the Flag-SOCS1 fragment, which was subcloned into the polylinker region of the PLP expression cassette at the same restriction sites. The PLP/SOCS1 vector was digested with ApaI and SacII (partial digestion) and a linear $15 \mathrm{~kb}$ transgene was isolated for microinjection into fertilized $(\mathrm{C} 57 \mathrm{BL} / 6 \mathrm{~J} \times \mathrm{DBA} / 2 \mathrm{~J})$ oocytes. Offspring positive for the transgene were identified by amplifying tail DNA by PCR using transgene-specific primers. The identified founders were subsequently bred with C57BL/6J mice (The Jackson Laboratory, Bar Harbor, ME) establishing a transgenic line.

IFN- $\gamma$-overexpressing mice. The transgenic mice $M B P / I F N-\gamma$ (line 172) and GFAP/tTA $\times$ TRE/IFN- $\gamma$ (lines 184/110 and 184/67) that overexpress IFN- $\gamma$ in the CNS have been described previously (Corbin et al., 1996; Gao et al., 2000; Lin et al., 2004, 2005). Briefly, MBP/IFN- $\gamma$ (line 172) mice are transgenic animals in which IFN- $\gamma$ expression is driven by the myelin basic protein (MBP) transcriptional control region (Gao et al., 2000). GFAP/tTA $\times$ TRE/IFN- $\gamma$ are double-transgenic mice obtained by mating single-transgenic GFAP/tTA (line 184) to single-transgenic TRE/ IFN- $\gamma$ (lines 110 and 67) mice. The two TRE/IFN- $\gamma$ mouse lines, line 110 and line 67, used in the experiments produce different amounts of IFN- $\gamma$ when crossed to GFAP/tTA mice (184/110 and 184/67) (Lin et al., 2004, 2005). GFAP/tTA $\times T R E / I F N-\gamma$ is a "tetracycline (tet)-off"-inducible system in which the glial fibrillary acidic protein (GFAP) transcriptional control region drives the expression of tetracycline-dependent transcription activator (tTA), which in turn, binds to the TRE (tet-responsive element) and initiates the expression of IFN- $\gamma$. Administration of doxycycline suppresses tTA DNA binding and IFN- $\gamma$ expression, and doxycycline removal allows for temporally controlled induction of IFN- $\gamma$ expression (Gao et al., 1999).

Mouse breeding and examination. IFN- $\gamma$-overexpressing mice were crossed to the PLP/SOCS1 mice in double-transgenic (MBP/IFN- $\gamma \times$ $P L P / S O C S 1)$ and triple-transgenic (GFAP/tTA $\times$ TRE/IFN- $\gamma \times P L P /$ SOCS1) mating systems. MBP/IFN- $\gamma \times P L P / S O C S 1(172 \times P L P /$ SOCS1) mating was performed according to a standard mating protocol. The GFAP/tTA $\times$ TRE/IFN- $\gamma \times P L P / S O C S 1$ matings were performed in a two-step mating process: GFAP/tTA mice (line 184) were initially crossed to PLP/SOCS1 mice, and double-positive $(184 \times$ PLP/SOCS1 $)$ offspring were then crossed to the TRE/IFN- $\gamma$ lines 110 and 67, separately. This second mating step was performed according to the previously described tet-off protocol. Doxycycline at $0.05 \mathrm{mg} / \mathrm{ml}$ (Sigma, St.
Louis, MO) was added to the water of impregnated female mice until embryonic day 14 , after which the animals were switched back to normal water, thereby allowing initiation of IFN- $\gamma$ transcription, which peaks during the postnatal period (Lin et al., 2005).

The litters of the mating systems (F1 generation) were examined daily and killed at postnatal day 21. Clinical evaluation included behavioral observation and challenged ladder walking to elicit tremor. Histological examination included quantitation of the number and density of oligodendrocytes and examination of the myelination patterns. Brain tissue was simultaneously obtained from each animal at the time of death to verify and measure the expression of IFN- $\gamma$ and Flag-SOCS1 (see below). The clinical and histological findings were subsequently stratified according to genotype. All animal procedures were conducted in compliance with the National Institutes of Health Guide for Care and Use of Laboratory Animals and were approved by the Institutional Animal Care and Use Committee at The University of Chicago.

PCR and genotyping. All experimental animals were genotyped using isolated tail DNA (Biotek 2000 automatic system; Beckman Coulter, Fullerton, CA). PCR (Qiagen PCR kit; Qiagen, Valencia, CA) for transgene detection was performed using the following transgene-specific screening primers: Flag-SOCS1 sense primer, 5'-CCAGGACGACGATGACAAGA-3'; Flag-SOCS1 antisense primer, 5'-TCAGGGGTCCCCAATAGAAG-3'; MBP/IFN- $\gamma$ sense primer, $5^{\prime}$-ATGAGGAAGAGCTGCAAAGC-3'; MBP/ IFN- $\gamma$ antisense primer, 5-GGTGACAGACTC CAAGCACA-3'; GFAP/tTA sense primer, $5^{\prime}$-TCGCTTTCCTCTGAACGCTTCTCG-3'; GFAP/tTA antisense primer, 5' -TCTGAACGCTGTGACTTGGAGTGTCC-3'; TRE/IFN- $\gamma$ sense primer $5^{\prime}$-CGAATTCGAGCTCGGTACCC- ${ }^{\prime}$; ; and TRE/IFN- $\gamma$ antisense primer $5^{\prime}$-CCATCCTTTGCCATTCCTCCAG-3' (Integrated DNA Technologies, Coralville, IA).

Northern blots and quantitative PCR. Total RNA was isolated from the examined animals with TRIzol reagent (Invitrogen, Carlsbad, CA). Northern blots were performed by separating $20 \mu \mathrm{g}$ of total RNA in a $1.2 \%$ denaturing agarose gel. The samples were transferred to a nylon membrane and hybridized overnight with an SOCS1 probe that had been randomly labeled by PCR (GenAmp2400; NEN/PerkinElmer, Wellesley, MA) with $\left[\alpha-{ }^{32} \mathrm{P}\right] \mathrm{dCTP}$ and $\left[\alpha-{ }^{32} \mathrm{P}\right] \mathrm{dATP}$ (NEN/PerkinElmer). Kodak film (Eastman Kodak, Rochester, NY) was exposed to the hybridized membrane at $-80^{\circ} \mathrm{C}$ for $48 \mathrm{~h}$ and was developed using the M7B Kodak processor (Eastman Kodak). To evaluate the relative levels of total RNA present in each lane the membrane was stripped and hybridized with a radiolabeled probe specific for the $28 \mathrm{~S}$ ribosomal RNA (Baerwald and Popko, 1998).

Quantitative-PCR (Q-PCR) (or real-time PCR) was performed by first reverse transcribing $1 \mu \mathrm{g}$ of DNAaseI-treated (Invitrogen) total RNA using oligo- $\mathrm{dT}_{12-18}$ and SuperScript II reverse transcriptase (Invitrogen RT-PCR kit). Q-PCR was performed using $20 \mathrm{ng}$ of the cDNA in a reaction containing iQSupermix and the following primers and probes for Flag-SOCS1 and IFN- $\gamma$ : Flag-SOCS1 sense primer, 5'GATGACAAGACGCGCCAGATG-3'; Flag-SOCS1 antisense primer, 5' GAGGACGAGGAGGGCTCTGA-3'; Flag-SOCS1 probe, $5^{\prime}$-56FAMCGCACCCAGCTGGC AGCCGACATT-3BHQ-1/-3'; IFN- $\gamma$ sense primer, 5'-GATATCTCGAGGAACTGGCAAAA-3'; IFN- $\gamma$ antisense primer, 5' CTACAAAGAGTCTGAGGTAGAAAGAGATAAT- ${ }^{\prime}$; IFN- $\gamma$ probe, $5^{\prime}$ FAM-TGGTGACATGAAAATCCTGCAGAGCCA-BHQ1-3'; glyceraldehyde-3-phosphate dehydrogenase (GAPDH) sense primer, 5' CTCAACTACATGGTCTACATGTTCCA-3'; GAPDH antisense primer, 5'-CCATTCTCGGCCTTGACTGT-3' , and GAPDH probe, 5' -5 TxRd-XN/ TGACTCCACTCACGGCAAATTCAACG-3BHQ-2-3' (Integrated DNA Technologies). The reactions were performed using a Bio-Rad (Hercules, CA) I-cycler real-time PCR unit, under the following conditions: 1 cycle at $95^{\circ} \mathrm{C}$ for $3 \mathrm{~min}, 40 \mathrm{cycles}$ at $95^{\circ} \mathrm{C}$ for $30 \mathrm{~s}$ and $60^{\circ} \mathrm{C}$ for $30 \mathrm{~s}$ (Bio-Rad). The mRNA levels of Flag-SOCS1 and IFN- $\gamma$ were normalized to the expression levels of GAPDH based on threshold cycles (Flag-SOCS1/GAPDH and IFN$\gamma /$ GAPDH ratios) (Lin et al., 2005).

Western blot and immunoprecipitation. Total lysates from brain and spleen of several PLP/SOCS1 mice and wild-type mice were obtained by tissue homogenization in radioimmunoprecipitation assay buffer (Santa Cruz Biotechnology, Santa Cruz, CA). After incubation on ice for $15 \mathrm{~min}$, lysates were centrifuged at 14,000 rpm for $30 \mathrm{~min}$, and the supernatants 
were collected. Protein samples (50 $\mu \mathrm{g}$ ) were electrophoresed on $15 \%$ SDS-polyacrylamide gels, transferred to polyvinylidene difluoride membranes (Trans-blot SD apparatus; Bio-Rad), incubated overnight with mouse anti-Flag antibody (M2, diluted to 1:1000; Sigma), and detected with ECL Western blot detection reagents (Amersham Biosciences, Piscataway, NJ). Flag protein (Sigma), a polymer of the Flag oligopeptide, was used as a positive control for the reaction.

Immunoprecipitation was performed with an immunoprecipitation kit (Roche Molecular Biochemicals, Indianapolis, IN) by incubating the protein extracts from the brain and spleen of PLP/SOCS1 and wild-type mice with anti-Flag antibody (M2) for $4 \mathrm{~h}$ at $4^{\circ} \mathrm{C}$, followed by overnight incubation with protein $\mathrm{A} / \mathrm{C}$ agarose at $4^{\circ} \mathrm{C}$. The immune complexes were collected by centrifugation at 14,000 rpm for 20S, and the protein was separated from protein $\mathrm{A} / \mathrm{C}$ agarose with kit-supplied reagents. Western blot of the immunoprecipitated protein was performed as described above.

Immunohistochemistry. Animals were anesthetized with $0.01 \mathrm{ml} / \mathrm{g}$ $2.5 \%$ Avertin (Sigma) administered intraperitoneally and perfused with saline, followed by $2 \%$ paraformaldehyde for $10 \mathrm{~min}$. Brains were removed, postfixed for $1 \mathrm{~h}$ with $2 \%$ paraformaldehyde, cryopreserved with $30 \%$ sucrose for $48 \mathrm{~h}$, prepared as frozen blocks (OCT compound; Sakura, Torrance, CA), and sectioned at a thickness of $7 \mu \mathrm{m}$ at $-20^{\circ} \mathrm{C}$ (CM1800 cryostat; Leica, Nussloch, Germany). Before immunostaining, the sections were treated with $0.1 \%$ Triton X-100 (Sigma) for $10 \mathrm{~min}$ and incubated with $10 \%$ bovine serum albumin (Sigma) or goat serum (Invitrogen) for $30 \mathrm{~min}$. Indirect immunostaining was performed by sequential incubation with primary antibodies (for $2 \mathrm{~h}$ at room temperature or overnight at $4^{\circ} \mathrm{C}$ ) and FITC-conjugated or cyanine 3 (Cy3)-conjugated secondary antibodies (for $30 \mathrm{~min}$ ). All of the following primary and secondary antibodies used in the study were commercially available: mouse and rabbit anti-Flag antibody (dilution, 1:100; Sigma), mouse anti-adenomatous polyposis coli protein (CC1) antibody (dilution, 1:20; Oncogene Sciences, Uniondale, NY), mouse MHC class I antibody (dilution, 1:100; Chemicon, Temecula, CA), mouse anti-PLP antibody (dilution, 1:100; Chemicon), mouse and rabbit anti-SOCS1 antibody (dilution, 1:100; Santa Cruz Biotechnology), rabbit anti-Stat 1 antibody (dilution, 1:100; Santa Cruz Biotechnology), anti-mouse or anti-rabbit FITC-conjugated secondary antibody (dilution, 1:100; Jackson ImmunoResearch, West Grove, PA), and anti-mouse or anti-rabbit Cy3congugated antibody (dilution, 1:500; Jackson ImmunoResearch). The immunostained sections were mounted using Vectashield mounting medium containing 4',6'-diamidino-2-phenylindole (DAPI) nuclear stain (Vector Laboratories, Burlingame, CA) and examined using a fluorescent microscope (Axoplan; Zeiss, Oberkochen, Germany).

Oligodendrocyte cell density was assessed digitally using Axiovision software (Zeiss), at postnatal day 21, as described previously (Lin et al., 2005). The brains were sectioned sagittally through the corpus callosum dividing the brain in two symmetrical halves. Ten frozen sections from each half were prepared at $7 \mu \mathrm{m}$ thickness and numbered in the sequence of their preparation. The brains of three animals per study group were prepared in this manner. After the CC1 immunostaining, the corresponding area of corpus callosum of each section was digitally selected, and the corresponding total area was obtained. CC1 cell counting was performed manually within the selected areas of each section, and the number of CC1-positive $\left(\mathrm{CCl}^{+}\right)$cells per square area (in square millimeter) was calculated. The results were presented as mean $\pm \mathrm{SD}$ of $\mathrm{CC} 1^{+}$cells $/ \mathrm{mm}^{2}$, with $n=3$ animals per study group.

Electron microscopy. Mice selected for electron microscopy studies were perfused with $4 \%$ paraformaldehyde and $2.5 \%$ glutaraldehyde. Brains were harvested, and white matter structures were sectioned using a stereotype microscope (Wild M3C; Wild AG, Heebrugg, Switzerland). The tissue was further postfixed in osmium tetroxide and embedded in freshly prepared epoxy resin (Epon-812; Electron Microscope Sciences, Fort Washington, PA) for $48 \mathrm{~h}$ at $60^{\circ} \mathrm{C}$. The resin blocks were sectioned at $90 \mathrm{~nm}$ using Leica Ultracut ultramicrotome (Leica) and stained with 5\% uracyl acetate and $2.5 \%$ lead citrate. Ultrastructure of the tissue samples was examined using the Tecnai-F30 transmission electron microscope (FEI Company, Hillsboro, OR).
Myelination patterns of the examined animals were assessed at postnatal day 21 by calculating the percentage of unmyelinated axons and ratio of the axon/fiber diameters (G ratio) with NIH Image J software as described previously (Lin at al., 2005). The brains were sectioned sagittally through the corpus callosum dividing the brain in two symmetrical halves. Approximately $2 \mathrm{~mm}^{3}$ samples from the genu and the splenum of both halves of corpus callosum were obtained using a Wild M3C stereotype microscope. The orientation of the specimen in the resin blocks yielding axonal cross-sections (well seen myelin rings) was chosen and established by toludine blue staining of a few sample sections. The resin blocks with the chosen orientation were processed for electron microscopic examination. Randomly selected areas were examined, and 10 representative pictures from both genu and splenum corpus callosum were obtained at $12,000 \times$ magnification. The number of unmyelinated axons was assessed by manual counting of axons that lacked myelin and were encircled solely by their own plasma membrane. All unmyelinated axons present in the representative images were counted, and their percentage was calculated by examining a total of 500 axons per tissue sample. The $\mathrm{G}$ ratio of myelinated axons was assessed by digitally selecting the area encircled by the inner and outer surfaces of the myelin sheath, obtaining the axonal (inner) and the fiber (outer) diameters and dividing their corresponding values (axonal diameter/fiber diameter ratio). The brains of three animals per group were examined, and the $\mathrm{G}$ ratios of a total of 150 nerve fibers from both genu and splenum were examined. The results were presented as mean $\pm \mathrm{SD}$ of $\mathrm{G}$ ratio and percentage unmyelinated axons, with $n=3$ animals per study group.

Mixed primary oligodendrocyte cultures and Stat1 translocation assay. Mixed primary oligodendrocyte cultures were prepared as described previously (Baerwald et al., 2000). Briefly, brain tissue was harvested from 2to 3-d-old newborn pups of PLP/SOCS1 and C57BL/6J matings. Because the litters contained transgenic and wild-type pups, the brain of each animal was processed individually and cultured separately, and later the genotype was matched. Each brain was digested separately using $0.25 \%$ trypsin and $10 \mu \mathrm{g} / \mathrm{ml}$ DNAaseI (Invitrogen) in DMEM for $20 \mathrm{~min}$ at $37^{\circ} \mathrm{C}$, and cells were cultured on separate poly-D-lysine-coated $75 \mathrm{~mm}^{2}$ flasks (Sigma). The cultures were maintained with $10 \%$ fetal bovine serum $/ \mathrm{DMEM}$ at $37^{\circ} \mathrm{C}$ with $5 \% \mathrm{CO}_{2}$ for $12 \mathrm{~d}$ and then switched to a defined medium containing $5 \mu \mathrm{l} / \mathrm{ml}$ insulin, $50 \mu \mathrm{g} / \mathrm{ml}$ transferrin, $30 \mathrm{~nm}$ selenium, $10 \mathrm{~nm}$ biotin, $10 \mathrm{~nm}$ progesterone, $15 \mathrm{~nm} \mathrm{T3}, 0.1 \%$ bovine serum albumin, and $1 \%$ ampicillin-streptomycin (Sigma). On the fifth day of differentiation, the cultures were treated with $100 \mathrm{U} / \mathrm{ml}$ IFN- $\gamma$ (Calbiochem, La Jolla, CA) for $30 \mathrm{~min}$. Dual immunostaining for anti-PLP and anti-Stat 1 antibodies and DAPI nuclear staining were performed as described above. The Stat 1 nuclear translocation assay was performed in six separate culture preparations. One hundred PLP-positive cells were manually counted in both wild-type and PLP/SOCS1 cultures. The results were presented as mean \pm SD percentage cells positive for Stat1 nuclear translocation.

Statistical analysis. All data were generated from three independent experiments. Means, SDs, and $p$ values were calculated using the Average, Stdev, and ANOVA functions in Microsoft (Redmond, WA) Excel. A statistically significant difference was defined as a $p$ value of $<0.05$.

\section{Results}

\section{Characterization of the PLP/SOCS1 transgenic mouse line}

The PLP/SOCS1 transgenic mice, which were generated as described in Material and Methods, were designed to express Flagepitope-tagged SOCS1 in myelinating cells (Fig. $1 A$ ). These mice exhibit no phenotypic abnormalities, breed and produce transgenic progeny in a Mendelian manner, and live a normal lifespan. Histological evaluation, including electron microscopy, performed at different time points up to 1 year of age revealed no significant differences in the myelination patterns or the number, density, or morphology of oligodendrocytes (see below) between transgenic and wild-type littermates.

Expression of the PLP/SOCS1 transgene was characterized at postnatal day 21 using several methods. Northern blot analysis with an SOCS1 cDNA hybridization probe revealed a band of 
increased intensity in RNA samples from the brains of transgenic mice relative to control brain samples but not from other tissues (Fig. $1 B$ ). Real-time PCR analysis with transgene-specific primers revealed the highest concentrations of transgenederived SOCS1 mRNA in brain, spinal cord, and sciatic nerve, with significantly lower levels in other organs, including heart, thymus, spleen, and liver (Fig. 1C). Transgene expression appeared to be stable up to 12 months of age (data not shown).

Western blot analysis, using an antibody to the Flag tag, revealed a $19 \mathrm{kDa}$ band corresponding to the expected size of SOCS1 in the PLP/SOCS1 brain lysates but not in wild-type brain lysates or PLP/ SOCS1 spleen lysates (Fig. $1 D$ ). To further confirm Flag-SOCS1 protein expression, we performed immunoprecipitation with the anti-Flag antibody, which again detected a $19 \mathrm{kDa}$ positive band in the PLP/ SOCS1 brain immunoprecipitates but not in the wild-type brain or PLP/SOCS1 spleen immunoprecipitates (Fig. $1 E$ ).

Indirect immunostaining of wild-type and PLP/SOCS1 brains with both antiSOCS1 and anti-Flag antibodies also demonstrated expression of the transgene (Fig. $1 F-I)$. We detected both anti-Flag and anti-SOCS1 immunopositivity only in PLP/SOCS1 brains.

To localize the expression of FlagSOCS1 in the CNS, we performed dual immunostaining of wild-type and PLP/ SOCS1 brain tissue with the anti-Flag antibody and either anti-PLP antibody, a marker for myelin, or anti-CC1 antibody, a marker for the oligodendrocyte cell body. We found a strong colocalization between anti-PLP and anti-Flag antibodies, as well as between anti-CC1 and antiFlag antibodies (data not shown), suggesting that Flag-SOCS1 was localized to the white matter and oligodendrocytes (Fig. 2). Noncolocalizing immunopositivity for anti-Flag, anti-PLP, or anti-CC1 antibodies was not detected.

We were also able to detect the expression of Flag-SOCS1 in primary mixed oligodendrocyte cultures established from transgenic animals by dual immunostaining with anti-PLP and anti-Flag antibodies (Fig. 3). Expression of Flag-SOCS1 was detected only in cultures from PLP/SOCS1 animals and only in cells expressing PLP. Virtually all PLP-positive cells were also positive for Flag-SOCS1. The colocalization between anti-Flag and anti-PLP immunoreactivity appeared to involve both the cell body and cell processes (Fig. $3 F$ ).

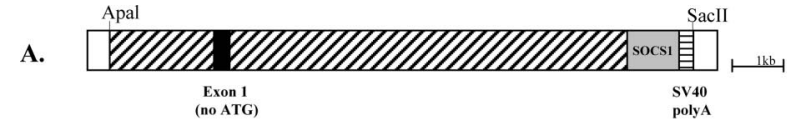

B.


E.

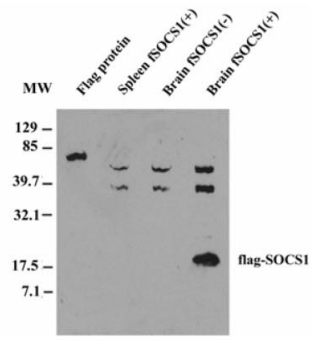

C.

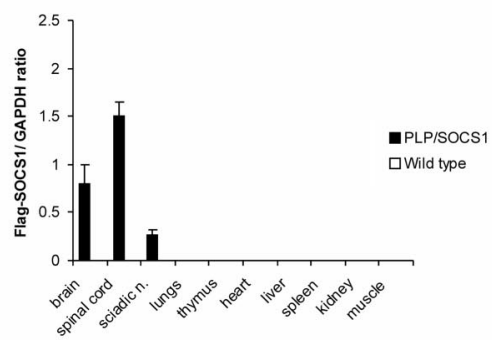

Organs

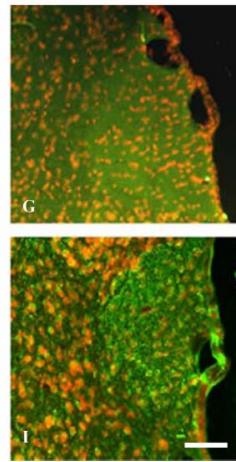

Figure 1. Expression of Flag-SOCS1. A, PLP/SOCS1 construct contains $2.4 \mathrm{~kb}$ of the PLP 5 ' flanking DNA, exon 1 (no ATG), intron 1 (diagonally striped boxes), Flag-SOCS1, and simian virus 40 (SV40) poly(A) signal sequence. Expression of the PLP/SOCS1 transgene was characterized at postnatal day 21 using several methods. $\boldsymbol{B}$, Northern blot analysis demonstrated Flag-SOCS1 expression in PLP/SOCS1 brain (lane 2; T, transgenic brain) compared with wild-type brain (lane 1; W, wild-type brain). C, Q-PCR analysis with transgene-specific primers revealed the highest concentrations of transgene-derived SOCS1 mRNA were in the brain, spinal cord, and sciatic nerve, with significantly lower levels in other organs. $\boldsymbol{D}$, Western blot. $\boldsymbol{E}$, Immunoprecipitation. Both demonstrated a single $19 \mathrm{kDa}$ Flag-positive band, the expected molecular weight (MW) of SOCS1, only in the lanes loaded with brain samples from PLP/SOCS1 mice (brain fSOCS1+). Flag protein was used as a positive control for the antibody reaction; 15\% SDS-PAGE, anti-Flag (M2) antibody. Immunostaining with anti-SOCS1/FITC $(\boldsymbol{F}, \boldsymbol{H}$, green) and anti-Flag/FITC ( $\boldsymbol{G}, \boldsymbol{I}$, green) antibodies demonstrated positive signal only in PLP/SOCS1 $(\boldsymbol{H}, \boldsymbol{I}$, green) and not in the wild-type mouse samples $(\boldsymbol{F}, \boldsymbol{G})$. Cell nuclei were contrastained with ethidium bromide ( $\boldsymbol{F}-\boldsymbol{I}$, red). Coronal sections of thalamic fiber are shown. Scale bar, $20 \mu \mathrm{m}$.
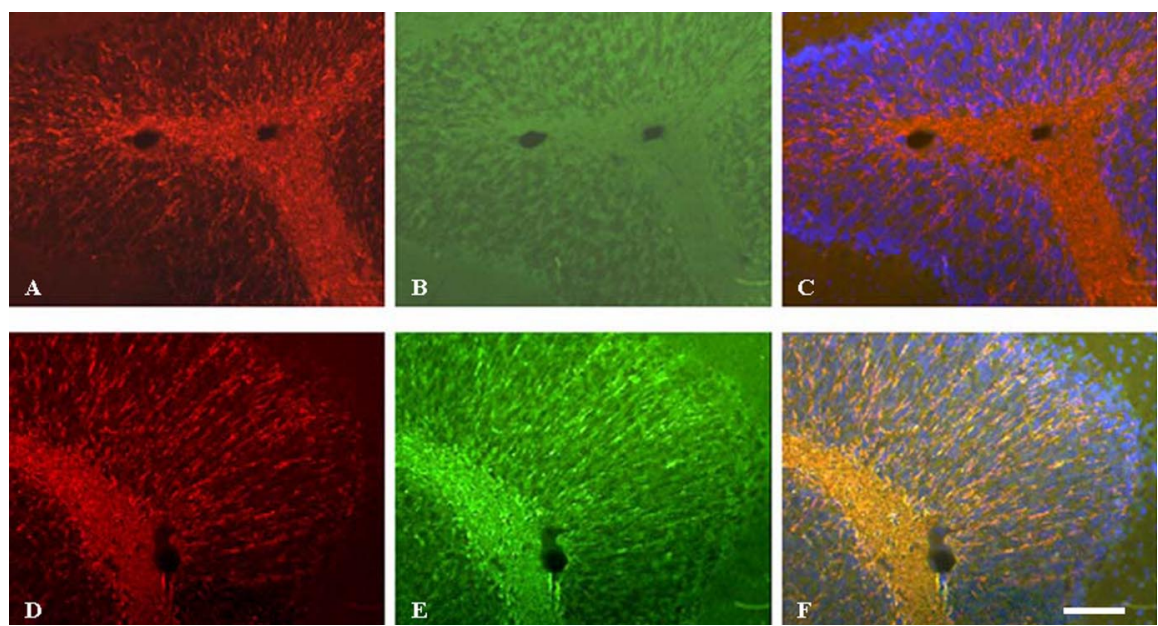

Figure 2. Colocalization of Flag-SOCS1 and PLP in vivo. Dual immunostaining of wild-type $(\boldsymbol{A}-\boldsymbol{C})$ and PLP/SOCS1 (D-F) cerebellar tissue, harvested at postnatal day 21, was performed using anti-PLP/Cy3 $(\boldsymbol{A}, \boldsymbol{D}$, red) and anti-Flag/FITC (B, $\boldsymbol{E}$, green) antibodies and DAPI nuclear stain ( $\boldsymbol{C}, \boldsymbol{F}$, blue). PLP-positive structures of the wild-type samples $(\boldsymbol{A}$, red) demonstrated no immunopositivity for anti-Flag $(\boldsymbol{B})$, and no signal colocalization was established (C). In contrast, PLP-positive structures of PLP/SOCSI samples $(\boldsymbol{D})$ expressed Flag-SOCS1 $(\boldsymbol{E})$, and strong colocalization between the anti-PLP and anti-Flag immunopositivity was detected ( $\boldsymbol{F}$, yellow color signifies colocalization). Sagittal sections of cerebellum are shown. Scale bar, $20 \mu \mathrm{m}$. 

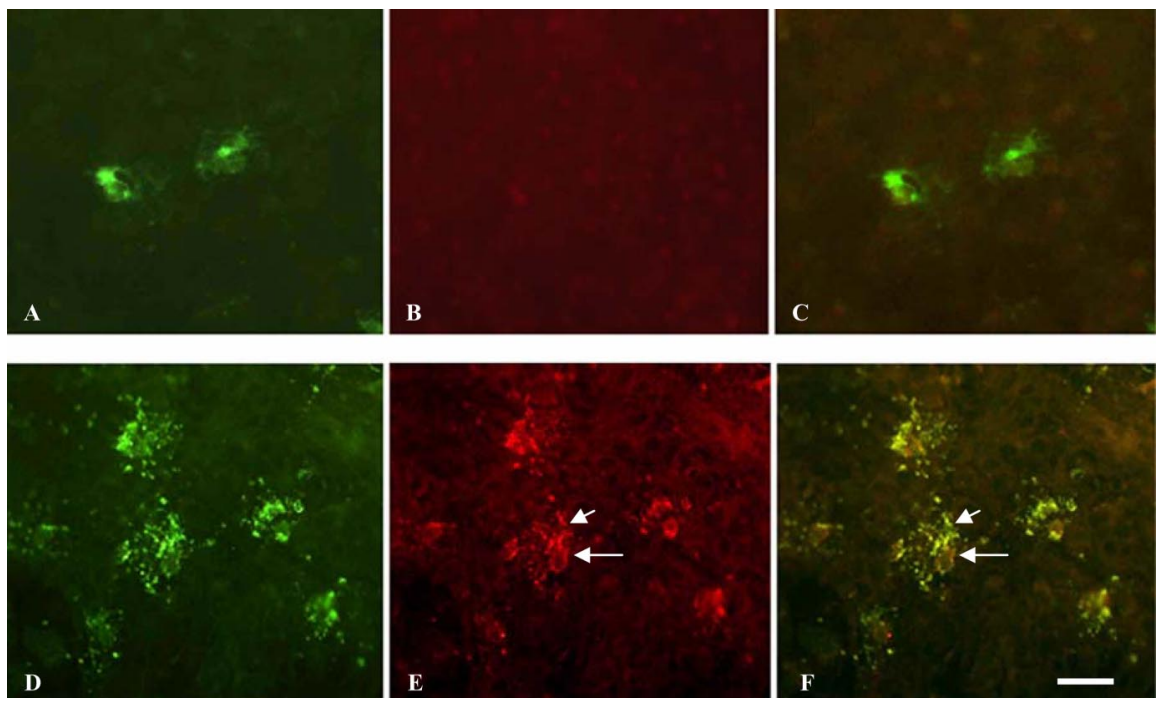

Figure 3. Colocalization of Flag-SOCS1 and PLP in vitro. Dual immunostaining of wild-type $(\boldsymbol{A}-\boldsymbol{C})$ and $P L P / S O C S 1(\boldsymbol{D}-\boldsymbol{F})$ mixed primary oligodendrocyte cultures was performed using anti-PLP/FITC $(\boldsymbol{A}, \boldsymbol{D}$, green) and anti-Flag/Cy3 $(\boldsymbol{B}, \boldsymbol{E}$, red) antibodies. PLP-positive oligodendrocytes in the wild-type culture $(\boldsymbol{A})$ demonstrated no immunopositivity for anti-Flag $(\boldsymbol{B})$, and no signal colocalization was established ( $\boldsymbol{C}$. In contrast, PLP-positive oligodendrocytes (D) in the PLP/SOCS1 cultures expressed Flag-S0CS1 $(\boldsymbol{E})$, and strong colocalization between anti-PLP and anti-Flag signals was detected $(\boldsymbol{F})$. Flag-SOCS1 appeared to be localized in the cell body (large arrows) and cell processes (small arrows) of oligodendrocytes. Scale bar, $20 \mu \mathrm{m}$.
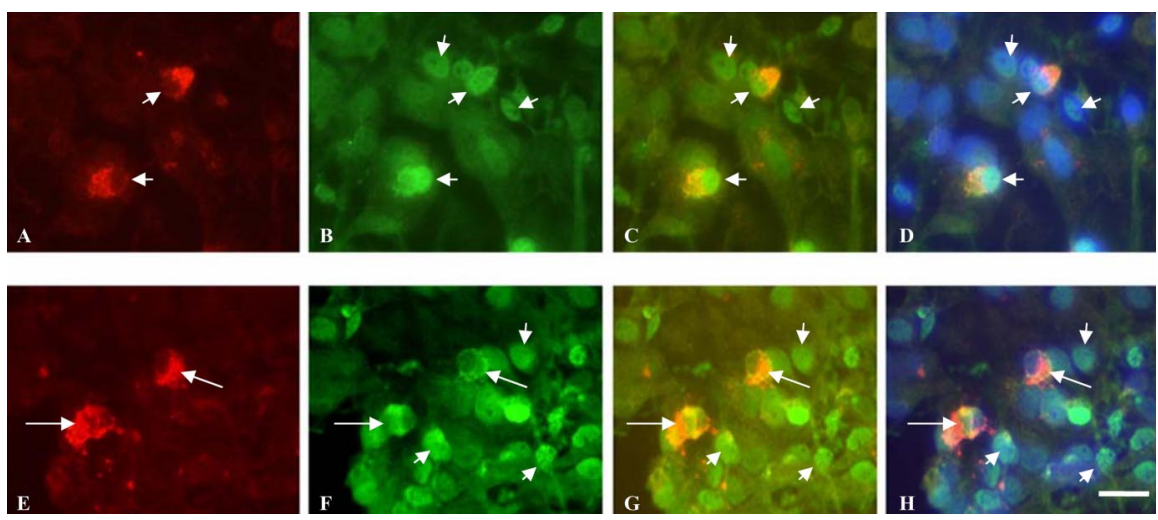

Figure 4. Differential inhibition of Stat1 nuclear translocation. Mixed primary oligodendrocyte cultures from wild-type $(\boldsymbol{A}-\boldsymbol{D})$ and PLP/SOCS1 (E-H) mice were stimulated with $100 \mathrm{U}$ of IFN- $\gamma$ for $30 \mathrm{~min}$, and dual immunostainings using anti-PLP/Cy3 (A, $\boldsymbol{E}$, red), anti-Stat1 ( $\boldsymbol{B}, \boldsymbol{F}$, green), and DAPI nuclear stain $(\boldsymbol{D}, \boldsymbol{H}$, blue) were performed and the fluorescent signals digitally overlaid ( $\boldsymbol{C}$, $\boldsymbol{G}$, overlay between PLP/Cy3 and Stat1/FITC signals; $\boldsymbol{D}, \boldsymbol{H}$, overlay between PLP/Cy3, Stat1/FITC, and DAPI signals). In the wild-type cultures, Stat1 was colocalized with DAPI-stained nuclei of all cells, including the PLP-positive oligodendrocytes (small arrows) (B, D, colocalization between Stat1 and DAPI). In the PLP/SOCS1 cultures, Stat1 was colocalized with DAPI-positive nuclei of the PLP-negative cells (small arrows) but not of the PLP-positive oligodendrocytes (large arrows) $(\boldsymbol{F}, \boldsymbol{H})$. Stat1 in the PLP-positive oligodendrocytes did not colocalize with DAPI-stained nuclei but remained in the cytoplasm (large arrows) $(\boldsymbol{F}, \boldsymbol{H})$. Scale bar, $10 \mu \mathrm{m}$.

\section{Oligodendrocytes from PLP/SOCS1 mice exhibited diminished responsiveness to IFN- $\gamma$}

The responsiveness of PLP/SOCS1 oligodendrocytes to IFN- $\gamma$ was studied in primary mixed glial cultures. To determine whether expression of transgenic SOCS1 would interfere with the nuclear translocation of the IFN- $\gamma$ signaling molecule Stat 1 , the cell cultures were treated with $100 \mathrm{U} / \mathrm{ml}$ IFN- $\gamma$ for $30 \mathrm{~min}$ and immunostained using anti-PLP and anti-Stat 1 antibodies along with the DAPI nuclear stain (Fig. 4). Examination of Stat1 subcellular localization in wild-type cultures revealed strong colocalization with DAPI-positive nuclei in all cells, including PLPpositive oligodendrocytes. In contrast, subcellular localization of Stat1 in PLP/SOCS1 cultures revealed a differential response to
IFN- $\gamma$. In transgenic PLP-positive oligodendrocytes, Stat1 remained in the cytoplasm and did not colocalize with cell nuclei in the presence of IFN- $\gamma$ (Fig. $4 E-H)$. This was in contrast to the response of the surrounding PLP-negative cells, which, similarly to wild-type cells, responded to IFN- $\gamma$ with Stat1 nuclear translocation. Virtually all PLP-positive oligodendrocytes (96 \pm 3 cells) in the wild-type cultures responded to IFN- $\gamma$ stimulation with Stat1 nuclear translocation. In contrast, Stat1 nuclear translocation was detected only in occasional PLP-positive oligodendrocytes $(6 \pm 2$ cells) after IFN- $\gamma$ stimulation $(p<0.05)$.

We next characterized the responsiveness of PLP/SOCS1 oligodendrocytes to IFN- $\gamma$ in vivo using the induction of MHC class I molecule expression as an indication of IFN- $\gamma$ sensitivity. The capacity of SOCS1 to inhibit IFN- $\gamma$-mediated induction of MHC class I molecule was examined in a double-transgenic system. MBP/ IFN- $\gamma$ (line 172) single-transgenic mice, which express a low level of IFN- $\gamma$ in the CNS (Gao et al., 2000), were mated to PLP/ SOCS1 mice, and the single- and doubletransgenic progeny were examined for differences in MHC class I molecule expression (Fig. 5). MHC class I molecule expression was detectable in neither control wild-type mice nor PLP/SOSC1 mice (Fig. 5A-D). Consistent with previous reports, $M B P / I F N-\gamma$ mice exhibited upregulated expression of the MHC class I molecule, with diffuse protein localization along the myelin sheath (Fig. 5E,F) (Corbin et al., 1996). The doubletransgenic mice $(M B P / I F N-\gamma \times P L P /$ SOCS1), however, displayed a differential pattern of MHC class I molecule expression (Fig. 5G-J). As shown in Figure 5, oligodendrocytes and myelin positive for Flag-tagged SOCS1 did not express detectable levels of MHC class I molecule, whereas cells negative for transgene expression, and in close proximity to the SOCS1-positive cells, demonstrated strong immunoreactivity (Fig. 5G-J). Similar differential upregulation of MHC class I molecule expression was observed after the direct administration of IFN- $\gamma$ in the brain of PLP/SOCS1 mice (data not shown). Together, these data indicate that oligodendrocytes from PLP/SOCS1 mice display diminished responsiveness to IFN- $\gamma$.

PLP/SOCS1 mice were protected against injurious IFN- $\gamma$ effects during development

Transgenic expression of IFN- $\gamma$ in the CNS of developing mice results in oligodendrocyte loss and hypomyelination (Corbin et al., 1996; Lin et al., 2005). To determine whether SOCS1 expression could protect developing oligodendrocytes from the injuri- 



Figure 5. Differential expression of MHC class I molecule in MBP/IFN- $\gamma \times P L P / S 0 C S 1$ mice. Wild-type $(\boldsymbol{A}, \boldsymbol{B}), P L P / S O C S 1(\boldsymbol{C}, \boldsymbol{D}), M B P / I F N-\gamma(\boldsymbol{E}, \boldsymbol{F})$, and $M B P / I F N-\gamma \times P L P / S O C S 1(\boldsymbol{G}-\boldsymbol{J})$ mouse brains, harvested at postnatal day 21, were dual immunostained with anti-MHC class I/FITC ( $\boldsymbol{A}, \boldsymbol{C}, \boldsymbol{E}, \mathbf{G}, \boldsymbol{I}$, green) and anti-flag/Cy3 ( $\boldsymbol{B}, \boldsymbol{D}, \boldsymbol{F}, \boldsymbol{H}, \boldsymbol{J}$, red) antibodies and DAPI nuclear stain $(\boldsymbol{J}$, blue). Wild-type samples were double negative $(\boldsymbol{A}, \boldsymbol{B})$. PLP/SOCS1 samples were negative for MHC class I molecule $(\boldsymbol{C})$ and positive for Flag (D). MBP/IFN- $\gamma$ samples were single positive for MHC class I molecule $(\boldsymbol{E})$ and negative for Flag $(\boldsymbol{F})$. Double-transgenic MBP/IFN- $\boldsymbol{\gamma} \times$ PLP/SOCS1 samples were double positive for MHC class I molecule $(\boldsymbol{G})$ and Flag $(\boldsymbol{H})$. Higher magnification of $M B P / I F N-\gamma \times$ PLP/SOCS1 samples (outlined square in $\boldsymbol{G}, \boldsymbol{H}$ ) revealed differential distribution of the immunopositivity $(\boldsymbol{I}, \boldsymbol{J})$; MHC class I-positive cells (large arrows) were negative for Flag, whereas Flag-positive cells (small arrows) were negative for MHC class I molecules. Sagittal sections of corpus callosum. Scale bars: $\boldsymbol{A}-\boldsymbol{H}, 20 \mu \mathrm{m} ; \boldsymbol{I}, \boldsymbol{J}, 10 \mu \mathrm{m}$.

Table 1. Incidence of tremor among the transgenic littermates

\begin{tabular}{lllcc}
\hline & Wild-type/controls & SOCS1 & IFN- $\gamma$ & IFN- $\gamma \times$ SOCS1 \\
\hline $172 \times$ PLP/SOCS1 & $0 \%$ & $0 \%$ & $0 \%$ & $0 \%$ \\
$184 / 110 \times$ PLP/SOCS1 & $0 \%$ & $0 \%$ & $80 \%(8$ of 10$)$ & $10 \%(1$ of 10$)$ \\
$184 / 67 \times P L P / S O C S 1$ & $0 \%$ & $0 \%$ & $100 \%(10$ of 10$)$ & $30 \%(3$ of 10$)$ \\
\hline
\end{tabular}

Littermates from three transgenic mating systems, $172 \times$ PLP/SOCS1, 184/110 $\times$ PLP/SOCS1, and 184/67 $\times$ PLP/SOCS1 were stratified according to their genotype into four groups: wild-type/control mice, mice expressing SOCS1 only, mice expressing IFN- $\gamma$ only, and mice expressing both IFN- $\gamma$ and SOCS1. Ten mice per group were clinically followed during the first 3 postnatal weeks, and the incidence of tremor was recorded.

ous effects of IFN- $\gamma$, we crossed PLP/SOCS1 mice to three transgenic mouse lines overexpressing IFN- $\gamma$ in the CNS at different levels, $M B P / I F N-\gamma$ (line 172), GFAP/tTA $\times$ TRE/IFN- $\gamma$ (lines 184/110), and GFAP/tTA $\times$ TRE/IFN- $\gamma$ (lines 184/67) and the following three mating systems were established (detailed in Material and Methods): MBP/IFN- $\gamma \times P L P / S O C S 1(172 \times P L P /$ SOCS1, a double-transgenic system) and GFAP/tTA $\times$ TRE/ IFN- $\gamma \times P L P / S O C S 1(184 / 110 \times P L P / S O C S 1$ and $184 / 67 \times P L P /$ SOCS1, two triple-transgenic systems). The litter (F1 generation) of each mating system was divided into four study groups depending on their genotype: wild-type/single-transgenic controls, mice expressing SOCS1 only, mice expressing IFN- $\gamma$ only, and mice expressing both IFN- $\gamma$ and SOCS1. A total of 40 animals per mating system (10 animals per each study group) were collected and examined clinically and histologically at postnatal day 21 .

Phenotypic comparisons of littermates were performed from birth to postnatal day 21, and evaluation consisted of behavioral observation and challenged ladder walking to elicit tremor. $\mathrm{MBP} /$ IFN- $\gamma$ (line 172) mice express low levels of IFN- $\gamma$ in the CNS and displayed no behavioral abnormalities, in accordance with findings reported previously (Corbin et al., 1996). Mice from the F1 generation of the MBP/IFN- $\gamma \times P L P / S O C S 1(172 \times P L P /$ SOCS1) mating system similarly displayed no behavioral abnormalities regardless of genotype. Double-transgenic GFAP/tTA $\times$ TRE/IFN- $\gamma$ (lines 184/110) and GFAP/tTA $\times$ TRE/IFN- $\gamma$ (lines184/67) mice display mild to moderate tremor that appears during the second postnatal week and peaks by $21 \mathrm{~d}$ of age (Lin et al., 2004, 2005). Mice from the F1 generation of the GFAP/tTA $\times$ TRE/IFN- $\gamma \times P L P / S O C S 1$ mating systems exhibited tremor, the incidence of which was dependent on genotype (Table 1). The phenotypes of wild-type mice and single-transgenic control mice
[GFAP/tTA (line 184), TRE/IFN- $\gamma$ (lines 67 and 110)] and PLP/ SOCS1 mice were clinically normal. The tremoring phenotype, which varied in severity, was identified in almost all doubletransgenic GFAP/tTA $\times$ TRE/IFN- $\gamma$ mice overexpressing IFN- $\gamma$ : $80 \%$ ( 8 of 10 ) of $184 / 110$ mice and $100 \%$ (10 of 10 ) of $184 / 67$ mice. Triple-transgenic GFAP/tTA $\times$ TRE/IFN- $\gamma \times P L P / S O C S 1$ mice overexpressing both IFN- $\gamma$ and SOCS 1 appeared to be protected, because only $10 \%$ ( 1 of 10 ) of $184 / 110 \times P L P / S O C S 1$ mice and $30 \%$ (3 of 10$)$ of $184 / 67 \times$ PLP/SOCS1 mice developed tremor (Table 1).

The clinically examined littermates of all three transgenic mating systems were further evaluated for histological abnormalities at postnatal day 21. Three animals per study group from each mating system were examined histologically for oligodendrocyte and myelin abnormalities. Brain tissue was obtained from each animal at the time of death (before the fixating perfusion), and total RNA was isolated. The possibility that SOCS1 expression affected the expression of the IFN- $\gamma$ transgene was examined in all three transgenic mating systems using Q-PCR (Fig. 6A). IFN- $\gamma$ expression was detected in $M B P / I F N-\gamma$ single-transgenic and $M B P /$ $I F N-\gamma \times P L P / S O C S 1$ double-transgenic littermates of the $172 \times$ $P L P / S O C S 1$ transgenic system in GFAP/tTA $\times$ TRE/IFN- $\gamma$ doubletransgenic and GFAP/tTA $\times$ TRE/IFN- $\gamma \times P L P / S O C S 1$ tripletransgenic littermates of the $184 / 110 \times P L P / S O C S$ transgenic system and in GFAP/tTA $\times$ TRE/IFN- $\gamma$ double-transgenic and GFAP/ $t T A \times T R E / I F N-\gamma \times P L P / S O C S 1$ triple-transgenic littermates of the $184 / 67 \times P L P / S O C 1$ transgenic system. Two characteristics of IFN- $\gamma$ expression were observed. First, the three mating systems differed in their expression levels: MBP/IFN- $\gamma \times$ PLP/SOCS1 $(172 \times$ PLP/SOCS1) expressed the lowest, and GFAP/tTA $\times$ TRE/ $I F N-\gamma \times P L P / S O C S 1(184 / 67 \times P L P / S O C 1)$ expressed the highest IFN- $\gamma$ levels. Second, the littermates of the same mating system, expressing IFN- $\gamma$ only or both IFN- $\gamma$ and SOCS1, did not differ in their expression levels. We found no detectible levels of IFN- $\gamma$ in the wild-type, the GFAP/tTA, and TRE/IFN- $\gamma$ single-transgenic and the PLP/SOCS1 littermates (Fig. 6A).

The cerebra of three animals per study group from all transgenic mating systems were processed for immunohistochemical analysis with the CC1 antibody to determine oligodendrocyte density (Figs. $6 B, 7$ ). The $M B P / I F N-\gamma$ mice expressed the lowest levels of IFN- $\gamma$ in the CNS compared with GFAP/tTA $\times$ TRE/ 
A.

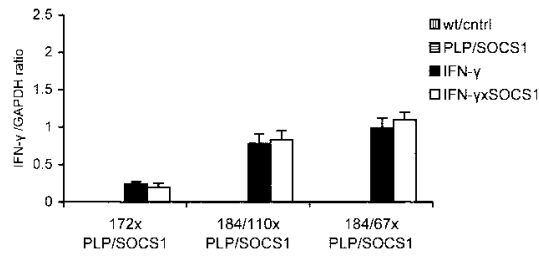

Matings

C.

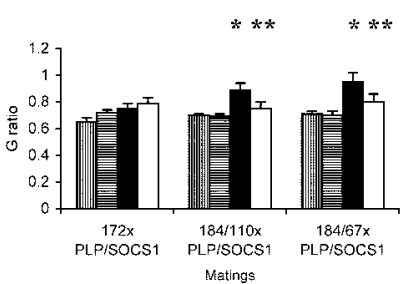

B.

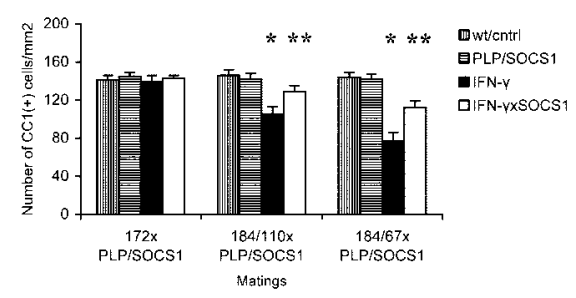

D.

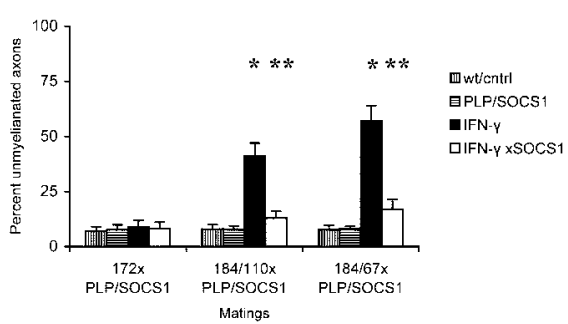

Figure 6. SOCS1-mediated protection of oligodendrocytes and myelin. The IFN- $\gamma$ expression $(\boldsymbol{A})$, oligodendrocyte density $\left(\mathrm{CC} 1\right.$ cells $\left./ \mathrm{mm}^{2}\right)(\boldsymbol{B}), \mathrm{G}$ ratio $(\boldsymbol{C})$, and percentage of unmyelinated axons $(\boldsymbol{D})$ were examined among littermates of three transgenic systems: $172 \times P L P / S O C S 1,184 / 110 \times P L P / S O C S 1$, and 184/67 $\times$ PLP/SOCS1 at postnatal day 21 (for a complete description, see Results). The relative amount of IFN- $\gamma$ expression differed among the systems, but no statistical difference was found in the levels of expression between littermates from the same transgenic system overexpressing either IFN- $\gamma$ only (IFN- $\gamma$ ) or both IFN- $\gamma$ and SOCS1 (IFN- $\gamma \times$ SOCS1) $(\boldsymbol{A})$. The IFN- $\gamma$-overexpressing littermates (IFN- $\gamma$ ) displayed significant dose-dependent oligodendrocyte cell loss ( $\boldsymbol{B})$ and hypomyelination ( $\boldsymbol{C}, \boldsymbol{D})$ compared with the wild-type, single-transgenic control (wt/cntrl), and PLP/SOCSI littermates ( ${ }^{*} p<0.05 ; n=3$ animals per study group). The triple-transgenic littermates expressing both IFN- $\gamma$ and SOCS1 $($ IFN- $\gamma \times$ SOCS1) displayed significant oligodendrocyte $(\boldsymbol{B})$ and myelin preservation $(\boldsymbol{C}, \boldsymbol{D})$ compared with those overexpressing IFN- $\gamma$ only $($ IFN- $\gamma){ }^{* *} p<0.05 ; n=3$ animals per study group).
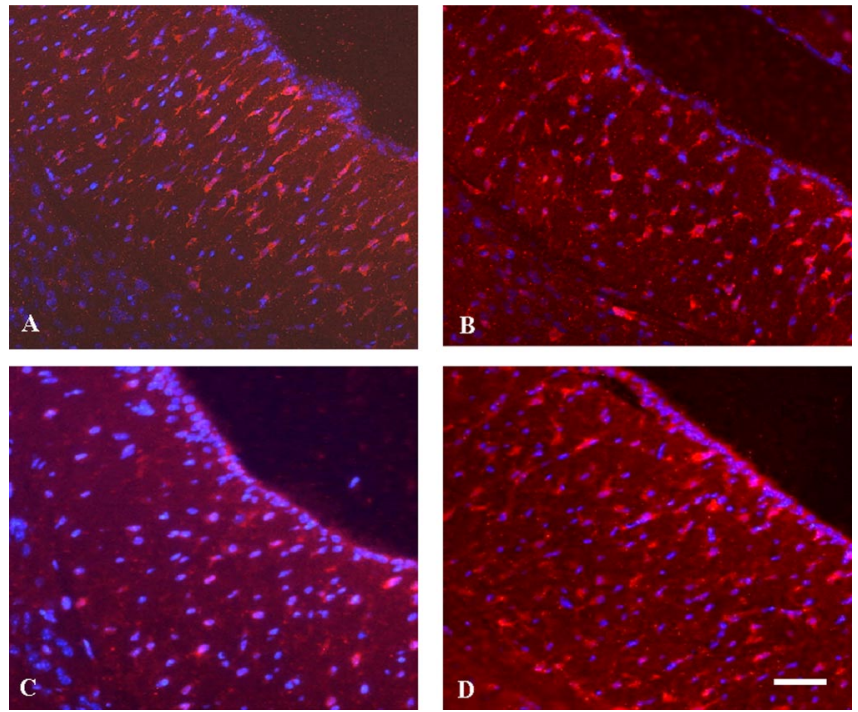

Figure 7. SOCS1-mediated oligodendrocyte protection. Representative images of the quantitated areas from GFAP/TTA $\times$ TRE/IFN- $\gamma \times P L P / S O C S 1(184 / 67 \times P L P / S O C S 1)$ mice at postnatal day 21: $\boldsymbol{A}$, wild type; $\boldsymbol{B}, P L P / S O C S 1 ; \boldsymbol{C}, 184 / 67$; and $\boldsymbol{D}, 184 / 67 \times P L P / S O C S 1$. Immunostaining with $\mathrm{CC} 1 / \mathrm{Cy} 3$ (red) and DAPI nuclear stain (blue). Sagittal sections of corpus callosum. Scale bar, $20 \mu \mathrm{m}$. Note the loss of $\mathrm{C} C 1$ positivity in the sample from an IFN- $\gamma$-overexpressing mouse (C) compared with the samples from wild-type $(\boldsymbol{A})$ and PLP/SOCST (B) mice, and the significant oligodendrocyte preservation in the sample from a mouse overexpressing both IFN- $\gamma$ and SOCS1 (D).

IFN- $\gamma$ mice and displayed no significant abnormalities in CC1positive cell density, in accordance with results reported previously (Gao et al., 2000). We found no statistically significant difference in the oligodendrocyte density among mice from the F1 generation of the MBP/IFN- $\gamma \times P L P / S O C S 1(172 \times P L P /$

SOCS1) mating system. In the tripletransgenic systems $($ GFAP/tTA $\times$ TRE/ $I F N-\gamma \times P L P / S O C S 1)$, we found that the oligodendrocyte density in mice from the F1 generation differed depending on genotype (Figs. $6 B, 7$ ). Wild-type mice and the single-transgenic mice (PLP/SOCS1, GFAP/tTA, and TRE/IFN- $\gamma$ ) had comparable oligodendrocyte densities. We found severe dose-dependent oligodendrocyte loss in the GFAP/tTA $\times$ TRE/IFN- $\gamma$ mice overexpressing IFN- $\gamma$ compared with the wild-type and single-transgenic littermates: $\sim 20 \%$ of oligodendrocytes were lost in 184/110 mice (from $146 \pm 6 \mathrm{CC}^{+}$ cells $/ \mathrm{mm}^{2}$ in the wild-type mice to $115 \pm 8$ $\mathrm{CC}^{+}$cells $/ \mathrm{mm}^{2}$ in the IFN- $\gamma$ mice), and $\sim 40 \%$ were lost in 184/67 mice (from $144 \pm 5 \mathrm{CCl}^{+}$cells $/ \mathrm{mm}^{2}$ in the wild-type mice to $79 \pm 9 \mathrm{CCl}^{+}$cells $/ \mathrm{mm}^{2}$ in the IFN- $\gamma$-overexpressing mice). In contrast, GFAP/tTA $\times$ TRE/IFN- $\gamma \times P L P / S O C S 1$ triple-transgenic littermates that overexpressed both IFN- $\gamma$ and SOCS1 lost statistically significantly fewer oligodendrocytes compared with mice overexpressing IFN- $\gamma$ only: $\sim 8 \%$ of oligodendrocytes were lost in 184/110 $\times$ PLP/SOCS1 mice (from $141 \pm 6 \mathrm{CCl}^{+}$cells $/ \mathrm{mm}^{2}$ in the PLP/SOCS1 mice to $129 \pm 6 \mathrm{CC}^{+}$cells/ $\mathrm{mm}^{2}$ in the IFN- $\gamma$ - and SOCS1-overexpressing mice), and $\sim 15 \%$ were lost in $184 / 67 \times$ PLP/SOCS1 mice (from $142 \pm 5$ $\mathrm{CCl}^{+}$cells $/ \mathrm{mm}^{2}$ in the PLP/SOCS1 mice to $112 \pm 7 \mathrm{CCl}^{+}$cells/ $\mathrm{mm}^{2}$ in the IFN- $\gamma$ - and SOCS1-overexpressing mice) (Figs. 6B, 7).

Myelination patterns in the harvested cerebra were further evaluated with electron microscopy, and the level of myelination was assessed by calculating the $G$ ratio and the percentage of unmyelinating axons (Figs. 6C,D, 8). We found no statistically significant difference in $\mathrm{G}$ ratios among wild-type, the singletransgenic, and double-transgenic littermates from the $M B P /$ IFN- $\gamma \times P L P / S O C S 1(172 \times P L P / S O C S 1)$ mating system. In the triple-transgenic systems $(G F A P / t T A \times T R E / I F N-\gamma \times P L P /$ SOCS1), significant differences in $\mathrm{G}$ ratios were found among the F1 generation mice, depending on genotype (Figs. $6 C$, 7). G ratios among the wild-type and the GFAP/tTA, TRE/IFN- $\gamma$, and PLP/ SOCS1 single-transgenic littermates were similar. IFN- $\gamma$ overexpressing GFAP/tTA $\times$ TRE/IFN- $\gamma$ littermates displayed significantly increased $\mathrm{G}$ ratios, indicating hypomyelination (defined as a $\mathrm{G}$ ratio $>0.8$ ): $0.89 \pm 0.02$ for $184 / 110$ mice and $0.95 \pm$ 0.04 for the $184 / 67$ mice (Fig. $6 C$ ). In contrast, their tripletransgenic $(G F A P / t T A \times T R E / I F N-\gamma \times P L P / S O C S 1)$ littermates overexpressing both IFN- $\gamma$ and SOCS1 had significantly lower G ratios: $0.75 \pm 0.03$ (within the normal range) for $184 / 110 \times$ PLP/SOCS1 mice and $0.82 \pm 0.08$ for $184 / 67 \times P L P / S O C S 1$ mice (Figs. 6C, 8).

The myelin abnormalities were further quantified by determining the percentage of unmyelinated axons in the various transgenic genotypes (Fig. 6D). We found no significant difference in the percentage of unmyelinated axons $(<9 \%)$ among the F1 generation littermates of the MBP/IFN- $\gamma \times$ PLP/SOCS1 $(172 \times$ PLP/SOCS1 $)$ double-transgenic system, regardless of genotype (Fig. $6 D$ ). In the triple-transgenic GFAP/tTA $\times$ TRE/ $I F N-\gamma \times P L P / S O C S 1$ systems, however, the distribution of 

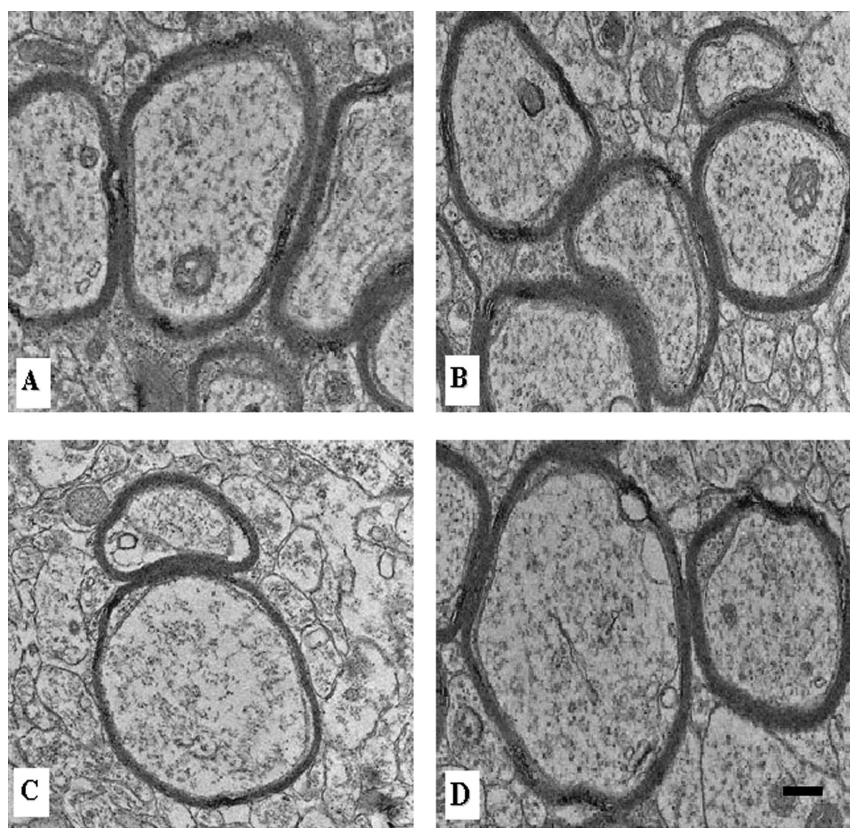

Figure 8. SOCS1-mediated myelin protection. Representative images of the quantitated areas from GFAP/tTA $\times$ TRE/IFN- $\gamma \times P L P / S O C S 1$ (184/67 $\times$ PLP/SOCS1) mice at postnatal day 21: $\boldsymbol{A}$, wild type; $\boldsymbol{B}, P L P / S O C S 1 ; \boldsymbol{C}, 184 / 67 ;$ and $\boldsymbol{D}, 184 / 67 \times P L P / S O C S 1$. Electron micrographs of corpus callosum. Scale bar, $500 \mathrm{~nm}$. Note the hypomyelination in the sample from an IFN- $\gamma$ overexpressing mouse $(\boldsymbol{C})$ compared with the samples from wild-type $(\boldsymbol{A})$ and PLP/SOCS1 $(\boldsymbol{B})$ mice and the significant myelin preservation in the sample from a mouse overexpressing both IFN- $\gamma$ and SOCS1 (D).

unmyelinated axons differed depending on genotype (Fig. 6D). There was a significantly increased percentage of unmyelinated axons in IFN- $\gamma$-overexpressing GFAP/tTA $\times$ TRE/IFN- $\gamma$ littermates compared with wild-type and single-transgenic control mice: $41 \pm 6 \%$ in 184/110 mice and $57 \pm 7 \%$ in $184 / 67$ mice. In contrast, triple-transgenic GFAP/tTA $\times$ TRE/IFN- $\gamma \times P L P /$ SOCS1 overexpressing both IFN- $\gamma$ and SOCS1 had a significantly lower percentage of unmyelinated axons compared with mice overexpressing IFN- $\gamma$ alone: only $13 \pm 3 \%$ for $184 / 110 \times P L P /$ SOCS1 mice and $17 \pm 4.5 \%$ for $184 / 67 \times$ PLP/SOCS1 mice (Fig. $6 D)$. Together, these data demonstrate that oligodendroglial expression of SOCS1 protects mice from the clinical and morphological consequences of IFN- $\gamma$ expression in the CNS during development.

\section{Discussion}

The presence of the T-cell-derived cytokine IFN- $\gamma$ within the CNS is believed to play a critical role in the pathogenesis of immune-mediated demyelinating disorders (Panitch et al., 1987; Vartanian et al., 1995; Horwitz et al., 1997; Glabinski et al., 1999; Tran et al., 2000; Steinman, 2001). Nevertheless, the cellular target of the effect of the cytokine remains unresolved. In this report, we describe the generation of transgenic mice in which the oligodendrocytes display a significantly reduced capacity to respond to IFN- $\gamma$. These mice are protected from the injurious effect of ectopic expression of IFN- $\gamma$ within the CNS, suggesting that a direct deleterious effect of IFN- $\gamma$ on oligodendrocytes contributes to immune-mediated disease pathogenesis. As discussed below, the work described has significant clinical implications.

Transgenic animals that ectopically express IFN- $\gamma$ in the CNS during postnatal development are hypomyelinated and contain reduced numbers of oligodendrocytes (Corbin et al., 1996; LeFerla et al., 2000; Lin et al., 2005). Moreover, the induction of
IFN- $\gamma$ expression in the CNS after demyelinating insults results in reduced oligodendroglial repopulation of the demyelinating lesions and impaired remyelination (Lin et al., 2006). Previously reported data from our laboratory suggests that the presence of IFN- $\gamma$ in the CNS activates an ER stress response in oligodendrocytes, which contributes to the observed pathological effects (Lin et al., 2005, 2006). It is unclear, however, whether the injurious effect of IFN- $\gamma$ on oligodendrocytes is a result of a direct action or whether it represents a secondary effect, possibly through microglial activation.

IFN- $\gamma$ has also been shown to have harmful effects on oligodendrocytes and their progenitors in vitro. There is considerable evidence to suggest that at least part of the injurious effect of this cytokine is mediated through the activation of microglial cells. IFN- $\gamma$-treated microglia release cytotoxic agents, including nitric oxide and tumor necrosis factor $\alpha$, which are known to be damaging to oligodendrocytes (Merrill and Zimmerman, 1991; Merrill et al., 1993, Loughlin et al., 1997). Studies using purified oligodendrocytes in vitro, however, suggest that the cytokine may have a direct, harmful effect on oligodendrocytes (Torres et al., 1995; Agresti et al., 1996; Andrews et al., 1998; Baerwald and Popko, 1998; Lin et al., 2005). IFN- $\gamma$ has been shown to inhibit cell cycle exit of oligodendroglial progenitor cells, which may predispose these cells to apoptotic death (Chew et al., 2005). Additionally, IFN- $\gamma$ has been shown to be a very powerful apoptosis-inducing agent for developing oligodendrocytes (Baerwald and Popko, 1998; Baerwald et al., 2000; Lin et al., 2005). Oligodendrocytes that have been allowed to differentiate in vitro to the point of expressing mature oligodendroglial markers are less sensitive to the presence of the cytokine, although they do eventually succumb to necrosis (Baerwald and Popko, 1998).

In an effort to differentiate direct versus indirect effects of IFN- $\gamma$ on oligodendrocytes in vivo, we generated transgenic mice that exhibited diminished oligodendrocyte-specific responsiveness to IFN- $\gamma$. Transgenic mice expressing either the dominantnegative form of IFN- $\gamma$ receptor subunit 1 (IFNGR1) or SOCS1 have been described previously (Flodstrom et al., 2001; Gonzales at al., 2005, Hindinger et al., 2005). Overexpression of the dominant-negative form of IFNGR1 resulted in accelerated degradation of wild-type IFNGR1 and elimination of the IFN- $\gamma$ cellular binding sites (Dighe et al., 1994). SOCS1 is an intracellular protein that blocks IFN- $\gamma$-mediated Stat1 activation (i.e., phosphorylation) by Jak kinases (Starr et al., 1997; Song and Shuai 1998; Stark et al., 1998; Sakamoto et al., 2000; Yasukawa et al., 2000; Levy and Darnell, 2002; Kubo et al., 2003). Mouse mutants with a targeted null mutation in the SOCS1 gene exhibit abnormal hypersensitivity to IFN- $\gamma$ and die of multiorgan failure in the presence of normal levels of the cytokine (Starr et al., 1998; Alexander et al., 1999; Bullen et al., 2001). Moreover, forced expression of SOCS1 has been shown to result in a state of IFN- $\gamma$ unresponsiveness in a variety of cell types (Chong et al., 2001; Flodstrom et al., 2001; Tunley et al., 2001, 2002; Federici et al., 2002).

The PLP/SOCS1 mice exhibited no phenotypic or histological abnormalities, indicating that Stat 1 activation is not required for normal oligodendrocyte development, although its involvement in growth factor signaling has been suggested in vitro (Dell'Albani et al., 1998). Our finding is supported by the phenotypic characteristics of Stat $1^{-1-}$ knock-out mice, which displayed no oligodendrocyte or myelin abnormalities but do have significantly impaired IFN- $\gamma$ cellular responses (Meraz et al., 1996). Thus, it appears that Stat 1 activation plays a differential role in oligodendrocyte injury and development. 
Functional examination of the PLP/SOCS1 mice further demonstrated a diminished oligodendrocyte-specific responsiveness to IFN- $\gamma$, including inhibition of Stat 1 activation (i.e., phosphorylation) and nuclear translocation and MHC class I molecule upregulation. When crossed with transgenic mice overexpressing IFN- $\gamma$ in the CNS, PLP/SOCS1 mice were protected from the deleterious clinical and histological effects of IFN- $\gamma$. IFN- $\gamma$ overexpressing transgenic mice that also carried the PLP/SOCS1 transgene displayed significant oligodendrocyte and myelin preservation and lower prevalence of tremor compared with IFN- $\gamma$ expressing mice without the PLP/SOCS1 transgene. Results of our study thereby indicate that IFN- $\gamma$ exerts a direct injurious effect on developing oligodendrocytes.

Overexpression of SOCS1 provided cellular protection to oligodendrocytes, suggesting that inhibition of IFN- $\gamma$ signaling results in reduced cellular effects. Wild-type oligodendrocytes, as reported by others and also observed by us, express nearly undetectable amounts of SOCS1 under normal, and even inflammatory, conditions and have much lower SOCS1 expression compared with the surrounding glial and inflammatory cells (Polizzotto et al., 2000; Maier et al., 2002; Wang and Campbell, 2002). Such low constitutive expression may limit the oligodendrocyte capacity for effective downregulation of IFN- $\gamma / \mathrm{Jak} / \mathrm{Stat} 1$ signaling, resulting in enhanced IFN- $\gamma$ cellular effects. The rescuing effect of SOCS1 overexpression in oligodendrocytes that was observed in our experimental system supports this possibility.

Circumstantial and experimental evidence suggests that IFN- $\gamma$ plays a deleterious role in the immune-mediated demyelinating disorder multiple sclerosis (Popko et al., 1997; Steinman, 2001). IFN- $\gamma$ is found in demyelinated lesions, and its levels in CSF correlate with disease severity (Vartanian et al., 1995; Calabresi et al., 1998; Becher et al., 1999; Moldovan et al., 2003). Administration of IFN- $\gamma$ to multiple sclerosis patients exacerbated the disease, and neutralizing antibodies to IFN- $\gamma$ have been shown to delay disease progression (Panitch et al., 1987; Skurkovich et al., 2001). Diminishing the local effect of IFN- $\gamma$, perhaps through the targeted expression of SOCS1 by oligodendrocytes, could prove to be therapeutically beneficial. Remyelinating oligodendrocytes after a demyelinating insult are more sensitive to the presence of IFN- $\gamma$ (Lin et al., 2006); therefore, such protection might be particularly useful for the promotion of remyelination.

Stem cell therapy is rapidly gaining interest as a potential therapeutic approach to demyelinating disorders such as multiple sclerosis and adrenoleukodystrophy (for review, see Keirstead, 2005). The success of such an approach would appear to be limited, however, in immune-mediated demyelinating disorders, because the harsh environment created by the inflammatory response would remain. Perhaps stem cells engineered to be resistant to the harmful cytokines present in the extracellular milieu of the breached CNS would stand a better chance of surviving and accomplishing remyelination. It is, therefore, of therapeutic interest to identify signaling pathways that play differential roles in oligodendrocyte injury and development. Our results describing inhibition of IFN- $\gamma$-mediated oligodendrocyte injury without induction of any observable oligodendrocyte or myelin abnormalities provide support for such an approach.

In summary, we have demonstrated that the forced expression of SOCS1 in oligodendrocytes of transgenic mice protects against the deleterious effects of IFN- $\gamma$ on oligodendrocytes and the process of myelination. Our results strongly indicate that the deleterious effect of IFN- $\gamma$ on myelinating oligodendrocytes is attrib- utable, at least in part, to a direct adverse effect on these cells. Moreover, our work suggests that forced expression of SOCS1 in oligodendrocytes might provide protection against the harsh environment in immune-mediated demyelinating disorders.

\section{References}

Agresti C, D’Urso D, Levi G (1996) Reversible inhibitory effects of interferon-gamma and tumor necrosis factor-alpha on oligodendroglial lineage cell proliferation and differentiation in vitro. Eur J Neurosci 8:1106-1116

Agresti C, Bernardo A, Del Russo N, Marziali G, Battistini A, Aloisi F, Levi G, Coccia E (1998) Synergistic stimulation of MHC class I and IRF-1 gene expression by IFN-gamma and TNF-alpha in oligodendrocytes. Eur J Neurosci 10:2975-2983.

Alexander W, Starr R, Fenner J, Scott C, Handman E, Spring N, Corbin J, Cornish, A Darwishe R, Owczarek C, Kay T, Nicola N, Hertzog P, Metcalf D, Hilton D (1999) Socs1 is a critical inhibitor of interferon-gamma signaling and prevents the potentially fatal action of this cytokine. Cell 98:598-608.

Andrews T, Zhang P, Bhat N (1998) TNFalpha potentiates IFN gammainduced cell death in oligodendrocyte progenitors. J Neurosci Res 54:574-583.

Baerwald K, Popko B (1998) Developing and mature oligodendrocytes respond differently to the immune cytokine interferon-gamma. J Neurosci Res 52:230-239.

Baerwald K, Corbin J, Popko B (2000) Major histocompatibility complex heavy chain accumulation in the endoplasmic reticulum of oligodendrocytes results in myelin abnormalities. J Neurosci Res 15:160-169.

Becher B, Giacomini PS, Pelletier D, McCrea E, Prat A, Antel J (1999) Interferon-gamma secretion by peripheral blood T-cell subsets in multiple sclerosis: correlation with disease phase and interferon-beta therapy. Ann Neurol 45:247-250.

Billiau A (1996) Interferon- $\gamma$ : biology and role in pathogenesis. Adv Immunol 62:61-130.

Bullen D, Darwich R, Metcalf D, Handman E, Alexander W (2001) Neutralization of interferon-gamma in neonatal SOCS1-/ - mice prevents fatty degeneration of the liver but not subsequent inflammatory disease. Immunology 104:92-98.

Calabresi P, Tranquill L, McFarland H, Cowan E (1998) Cytokine gene expression in cells derived from CSF of multiple sclerosis patients. J Neuroimmunol 14:198-205.

Chew L, King W, Kenedy A, Gallo V (2005) Interferon-gamma inhibits cell cycle exit in differentiating oligodendrocyte progenitor cells. Glia 52:127-143.

Chong M, Thomas H, Kay T (2001) gamma-Interferon signaling in pancreatic beta-cells is persistent but can be terminated by overexpression of suppressor of cytokine signaling-1. Diabetes 50:2744-2751.

Corbin J, Kelly D, Rath E, Baerwald K, Suzuki K, Popko B (1996) Targeted CNS expression of interferon-gamma in transgenic mice leads to hypomyelination, reactive gliosis, and abnormal cerebellar development. Mol Cell Neurosci 7:354-370.

Dell'Albani, Kahn M, Cole R, Condorelli D, Giuffrida-Stela A, Vellis J (1998) Oligodendrocyte survival factors, PDGF-AA and CNTF, activate Jak/ STAT signaling pathways. J Neurosci Res 54:191-205.

Dighe A, Richards E, Old L, Schreiber R (1994) Enhanced in vivo growth and resistance to rejection of tumor cells expressing dominant negative IFN gamma receptors. Immunity 1:447-456.

Doerflinger N, Macklin W, Popko B (2003) Inducible site-specific recombination in myelinating cells. Genesis 35:63-72.

Einhauer A, Jungbauer A (2001) The flag peptide, a versatile fusion tag for the purification of recombinant proteins. J Biochem Biophys 49:455-465.

Federici M, Giustiziri M, Scarponi C, Girolomini G, Albanesi C (2002) Impaired IFN-gamma-dependent inflammatory response in human keratinocytes overexpressing the suppressor of cytokine signaling 1 . J Immunol 169:434-443.

Flodstrom M, Maday A, Balakrisha D, Cleary M, Yoshimura A, Starvetnick N (2001) Target cell defense prevents development of diabetes after viral infection. Nat Immunol 3:373-382.

Fuss B, Mallon B, Phan T, Ohlemeyer C, Kirchoff F, Nishiyama A, Macklin W (2000) Purification and analysis of in vivo-differentiated oligodendrocytes expressing the green fluorescent protein. Dev Biol 218:259-274. 
Gao X, Kemper A, Popko B (1999) Advanced transgenic and gene-targeting approaches. Neurochem Res 24:1183-1190.

Gao X, Gilling T, Ye P, D’Ercole J, Matsushima G, Popko B (2000) Interferon- $\gamma$ protects against cuprizone-induced demyelination. Mol Cell Neurosci 16:338-349.

Glabinski A, Krakowski M, Han Y, Owens T, Ransohoff R (1999) Chemokine expression in GRO mice (lacking interferon-gamma) with experimental autoimmune encephalomyelitis. J Neurovirol 51:95-101.

Gonzales J, Bergmann C, Fuss B, Hinton D, Kangas C, Macklin W, Stohlman $S$ (2005) Expression of dominant negative IFN- $\gamma$ receptor on mouse oligodendrocytes. Glia 51:22-34.

Hindinger C, Gonzalez J, Bergmann C, Fuss B, Hinton D, Atkinson R, Macklin W, Stohlman S (2005) Astrocyte expression of a dominant-negative interferon-gamma receptor. J Neurosci Res 82:20-31.

Horwitz M, Evans C, McGavern D, Rodriguez M, Oldstone M (1997) Primary demyelination in transgenic mice expressing interferon-gamma. Nat Med 3:1037-1041.

Keirstead H (2005) Stem cells for the treatment of myelin loss. Trends Neurosci 28:677-683.

Kubo M, Hanada T, Yoshimura A (2003) Suppressors of cytokine signaling and immunity. Nat Immunol 4:1169-1176.

LaFerla F, Sugarman M, Lane T, Leissring M (2000) Regional dysplasia in transgenic mice with astrocyte-derived expression of interferon-gamma. J Mol Neurosci 15:45-59.

Levy D, Darnell J (2002) Stats: transcriptional control and biological impact. Nat Rev Mol Cell Biol 3:651-662.

Lin W, Kemper A, McCarthy K, Pytel P Wang J, Campbell I, Utset M, Popko B (2004) Interferon- $\gamma$ induces medulloblastoma in the developing cerebellum. J Neurosci 24:10074-10083.

Lin W, Harding H, Ron D, Popko B (2005) Endoplasmic reticulum stress modulates the response of myelinating oligodendrocytes to the immune cytokine interferon-gamma. J Cell Biol 169:603-612.

Lin W, Kemper A, Dupree J, Harding H, Ron D, Popko B (2006) Interferongamma inhibits central nervous system remyelination through a process modulated by endoplasmic reticulum stress. Brain 129:1306-1318.

Loughlin A, Copelman C, Hall A, Armer T, Young B, Landon D, Cuzner M (1997) Myelination and remyelination of aggregate rat brain cell cultures enriched with macrophages. J Neurosci Res 47:384-392.

Maier J, Kincaid C, Pagenstecher A, Campbell I (2002) Regulation of signal transducer and activator of transcription and suppressor of cytokinesignaling gene expression in the brain of mice with astrocyte-targeted production of interleukin-12 or experimental autoimmune encephalomyelitis. Am J Pathol 160:271-288.

Meraz M, White J, Sheehan K, Bach E, Roding S, Dighe A, Kaplan D, Riley J, Greenlund A, Campbell D, Caver-Moore K, Dubois R, Clark R, Aguet M, Schreiber R (1996) Targeted disruption of Statl gene in mice reveals unexpected physiological specificity in the Jak/STAT signaling pathway. Cell 84:431-442.

Merrill J, Zimmerman R (1991) Natural and induced cytotoxicity of oligodendrocytes by microglia is inhibitable by TGF beta. Glia 4:327-331.

Merrill J, Ignarro L, Sherman M, Melinek J, Lane T (1993) Microglial cytotoxicity of oligodendrocytes is mediated through nitric oxide. J Immunol 151:2132-2141.

Moldovan IR, Rudick RA, Cotleur AC, Born SE, Lee JC, Karafa MT, Pelfrey CM (2003) Interferon gamma responses to myelin peptides in multiple sclerosis correlate with a new clinical measure of disease progression. J Neuroimmunol 141:132-140.
Panitch N, Hirsch R, Haley A, Johnson K (1987) Exacerbations of multiple sclerosis in patients treated with gamma interferon. Lancet 1:893-895.

Polizzotto M, Bartlett P, Turnley A (2000) Expression of "suppressor of cytokine signaling" (SOCS) genes in the developing and adult mouse nervous system. J Comp Neurol 423:348-358.

Popko B, Corbin J, Baerwald K, Dupree J, Garcia A (1997) The effects of interferon-gamma on the central nervous system. Mol Neurobiol 14:19-35.

Pouly S, Becher B, Blain M, Antel J (2000) Interferon-gamma modulates human oligodendrocyte susceptibility to Fas-mediated injury. J Neuropathol Exp Neurol 59:280-286.

Sakamoto H, Kinjyo I, Yoshimura A (2000) The janus kinase inhibitor, Jab/ SOCS1, is an interferon-gamma inducible gene and determines sensitivity to interferons. Leuk Lymphoma 38:49-58.

Skurkovich S, Boiko A, Beliaeva I, Buglak I, Alekseeva T, Smirnova T, Kulakova O, Tchechonin V, Gurova O, Deomina T, Favarova O, Skurkovith B, Gusev E (2001) Randomized study of antibodies to IFN-gamma and TNF-alpha in secondary progressive multiple sclerosis. Mult Scler 7:277-284.

Song M, Shuai K (1998) The suppressor of cytokine signaling (SOCS1) and SOCS3 but not SOCS2 proteins inhibit interferon-mediated antiviral and antiproliferative activities. J Biol Chem 25:35056-35062.

Stark G, Kerr I, Williams B, Silverman R, Schreiber R (1998) How cells respond to interferons. Annu Rev Biochem 67:257-264.

Starr R, Wilson T, Viney E, Murray L, Rayner J, Jenkins J, Brendan J, Gonda T, Alexander W, Metcalf D, Nicola N, Hilton J (1997) A family of cytokine inducible inhibitors of signaling. Nature 387:917-921.

Starr R, Metcalf D, Elefanty AG, Brysha M, Wilson TA, Nicola NA, Hilton DJ, Alexander WS (1998) Liver degeneration and lymphoid deficiency in mice lacking suppressor of cytokine signaling-1. Proc Natl Acad Sci USA 95:14395-14399.

Steinman L (2001) Blockade of gamma interferon might be beneficial in MS. Mult Scler 7:275-276.

Torres C, Aranguez I, Rubio N (1995) Expression of interferon-gamma receptors on murine oligodendrocytes and its regulation by cytokines and mitogens. Immunology 86:250-255.

Tran E, Prince E, Owens T (2000) IFN-gamma shapes invasion of the central nervous system via regulation of chemokines. J Immunol $164: 2759-2768$.

Traugott U (2001) Evidence for immunopathogenesis. In: Handbook of multiple sclerosis, Ed 3 (Cook S, ed), pp 163-192. New York: Dekker.

Tunley A, Starr R, Bartlett P (2001) SOCS1 regulates interferon-gamma mediated sensory neuron survival. NeuroReport 16:3443-3445.

Tunley A, Starr R, Bartlett P (2002) Failure of sensory neurons to express class I MHC is due to differential SOCS1 expression. J Neuroimmunol 123:35-40.

Vartanian T, Li Y, Zhao M, Stefansson K (1995) Interferon- $\gamma$ induced oligodendrocyte cell death: implications for the pathogenesis of multiple sclerosis. Mol Med 1:732-743.

Wang J, Campbell I (2002) Cytokine signaling in the brain: putting a SOCS in it? J Neurosci Res 67:423-427.

Wight P, Duchala C, Readhead C, Macklin W (1993) A myelin proteolipid protein-lacZ fusion protein is developmentally regulated and targeted to the myelin membrane in transgenic mice. J Cell Biol 123:443-454.

Yasukawa H, Sasaki A, Yoshimura A (2000) Negative regulation of signaling pathways. Annu Rev Immunol 18:143-164. 